Technical Note

\title{
Bluetooth-Beacon-Based Underground Proximity Warning System for Preventing Collisions inside Tunnels
}

\author{
Jieun Baek ${ }^{\mathbb{D}}$ and Yosoon Choi * $\mathbb{D}$ \\ Department of Energy Resources Engineering, Pukyong National University, Busan 48513, Korea; \\ bje0511@gmail.com \\ * Correspondence: energy@pknu.ac.kr or yspower7@gmail.com; Tel.: +82-51-629-6562
}

Received: 1 October 2018; Accepted: 13 November 2018; Published: 16 November 2018

\begin{abstract}
Collisions between pieces of equipment as well as between equipment and workers frequently occur inside underground tunnels, owing to limited visibility coupled with a confined work environment. To address this problem, a Bluetooth-beacon-based proximity warning system (PWS) capable of preventing collisions inside underground tunnels has been proposed. The proposed PWS receives signals from Bluetooth beacons attached to bodies of mine workers and/or their equipment via smartphones installed in vehicles, thereby providing drivers with primary (caution) and secondary (warning) alerts in stages, based on the intensity of received signals. After identifying suitable received signal strength indicator (RSSI) threshold values corresponding to the caution and warning zones, a field test was performed inside an underground tunnel based on results obtained from a preliminary experiment. Using collective results obtained during 50 experimental repetitions, the accuracies of the first and second alert occurrences in the caution and warning zones were determined to be $93 \%$ and $95 \%$, respectively. The proposed Bluetooth-beacon-based PWS was demonstrated to be effective for preventing collisions inside underground tunnels. In addition, the proposed system is relatively inexpensive, and its functions can easily be extended via the use of smartphone applications.
\end{abstract}

Keywords: underground tunnels; Bluetooth beacon; smartphone; safety management; App Inventor

\section{Introduction}

Collisions not only between pieces of equipment but also between equipment and mine workers frequently occur inside underground mines, which are narrow and dark [1]. According to mine disaster statistics issued by the Centers for Disease Control and Prevention (CDC), accidents involving mining equipment inside underground mining sites in the United States have accounted for 37 deaths since 1984, and 16 workers have been killed in crashes involving shuttle cars and buckets between 2000 and 2010 [2]. Moreover, nearly 47\% of all deaths that have occurred in underground mines between 2011 and 2015 have been caused by collisions between equipment and workers [3].

To prevent the occurrence of said collisions between pieces of equipment as well as between equipment and workers inside underground mines, proximity warning systems (PWSs) involving the use of electromagnetic- or magnetic-field sensors have been developed and used in the past [4]. A PWS provides collision risk warnings when workers and equipment come within a certain distance of each other [5]. Similar to PWSs, other proposed technologies intended for collision prevention include proximity detection systems (PDSs), which are devices that detect the approach of a piece of equipment or a worker through use of sensors, and collision avoidance systems (CASs), which involve the use of devices that effect maneuvers to avoid the occurrence of potentially fatal collisions $[5,6]$. 
The National Institute for Occupational Safety and Health (NIOSH) in the United States has performed numerous studies concerning the development of PWSs for mining sites. Ruff [7] performed an experiment to detect obstacles in blind spots in the driver's field of view via the use of various sensors attached to a 50-ton dumping truck. Based on the results of these experiments, he subsequently analyzed the reliability and false alarm rate of the proximity-detection technology using sensors [8]. Ruff and Hession-Kunz [9] developed a PWS using radio-frequency identification (RFID) technology. Using a set frequency of $315 \mathrm{MHz}$, the said system received radio signals from tags through a reader and provided progressive collision-risk signals (far, medium-range, and near) for objects approaching blind spots. Commercialized RFID-based PWSs currently include the underground collision avoidance system (UCAS) by Becker Mining Systems [10] and IMPACT, developed by Mine Site Technologies [11]. Schiffbauer [4] developed a hazardous area signaling and ranging device (HASARD) capable of detecting the approach of equipment and workers towards a continuous mining machine (CMM) by means of a magnetic transceiver. This system was capable of detecting a $60-\mathrm{kHz}$ band magnetic field transmitted by wire-loop antennas at the receiver end. In the event of a collision risk, the system provided equipment operators with visible, audible, and vibrational signals. Other PWSs employing magnetic-field sensors include the PBE Group's proximity alert system [12], Strata's HazardAvert [13], and NAUTILUS International's buddy proximity detection system [14].

Recently, attempts have been made to develop PWSs using Bluetooth low energy (BLE), which corresponds to Bluetooth 4.0 wireless communication technology. Based on the IEEE 802.15.1 communication standard corresponding to the 2.4-GHz frequency band, the use of BLE serves to reduce power consumption as well as packet size, thereby enabling faster data transmission $[15,16]$. Park et al. [17] developed PWS using Bluetooth beacons for preventing collisions between workers and equipment used at construction sites. Bluetooth beacons are devices that periodically transmit BLE signals. PWS devices developed in Reference [17] received signals from multiple Bluetooth beacons installed on dumping trucks and wheel loaders via the use of a smartphone, and provided workers with collision warnings. Park et al. [18] proposed a safety-monitoring-system framework to integrate the said Bluetooth-beacon-based location-detection technology with building information model (BIM)-based hazard identification and a cloud-based communication platform. The integrated system successfully demonstrated the capacity to detect unsafe operating conditions, as well as collect and analyze trajectories of workers with respect to potential safety hazards in buildings. Park et al. [19] investigated inconsistencies and delays occurring in the operation of Bluetooth-beacon-based PWSs owing to variations caused by different settings and environmental conditions, such as equipment types and approaching speeds. Their study also discussed parameter adjustment and the use of adaptive signal-processing methods to reduce inconsistencies in alert distances and time delays resulting from the use of different types of equipment and high approaching speeds, respectively. Although Bluetooth-beacon-based PWSs have only been recently developed and investigated for use in civil and construction industries, little attention has been paid to the possibility of employing Bluetooth-beacon-based PWSs in underground tunnels. This possibility must be investigated to extend the utility of Bluetooth-beacon-based PWSs to the mining industry.

The purpose of this study was to develop a Bluetooth-beacon-based underground proximity warning system (BBUNPROWS) for use in underground tunnels. A smartphone application that provided drivers with progressive collision-risk alarms based on the status of a received signal strength indicator (RSSI) was developed. The said alarms were issued after the receipt of signals-transmitted by Bluetooth beacons attached to workers and equipment inside a tunnel—by a smartphone mounted on a moving equipment. This manuscript describes the development of the proposed BBUNPROWS along with the presentation of results obtained during field tests performed inside an underground tunnel.

\section{Design of Proposed Bluetooth-Beacon-Based PWS}

As already mentioned, the proposed PWS system received signals from Bluetooth beacons and provided drivers with progressive collision alerts (Figure 1). Inside an underground tunnel, Bluetooth 
beacons were installed on the safety helmets of workers, the rears of vehicles, and at potentially dangerous locations. In addition, "caution" and "warning" zones, wherein the first and second alerts, respectively, are to be provided, were defined along the direction of motion of a vehicle equipped with a smartphone. Signals transmitted from pedestrian workers, the preceding vehicle, and Bluetooth beacons installed at dangerous locations were received by the smartphone mounted on the vehicle so that the primary (caution) and secondary (warning) alerts could be provided to the driver progressively, in accordance with corresponding RSSI values.

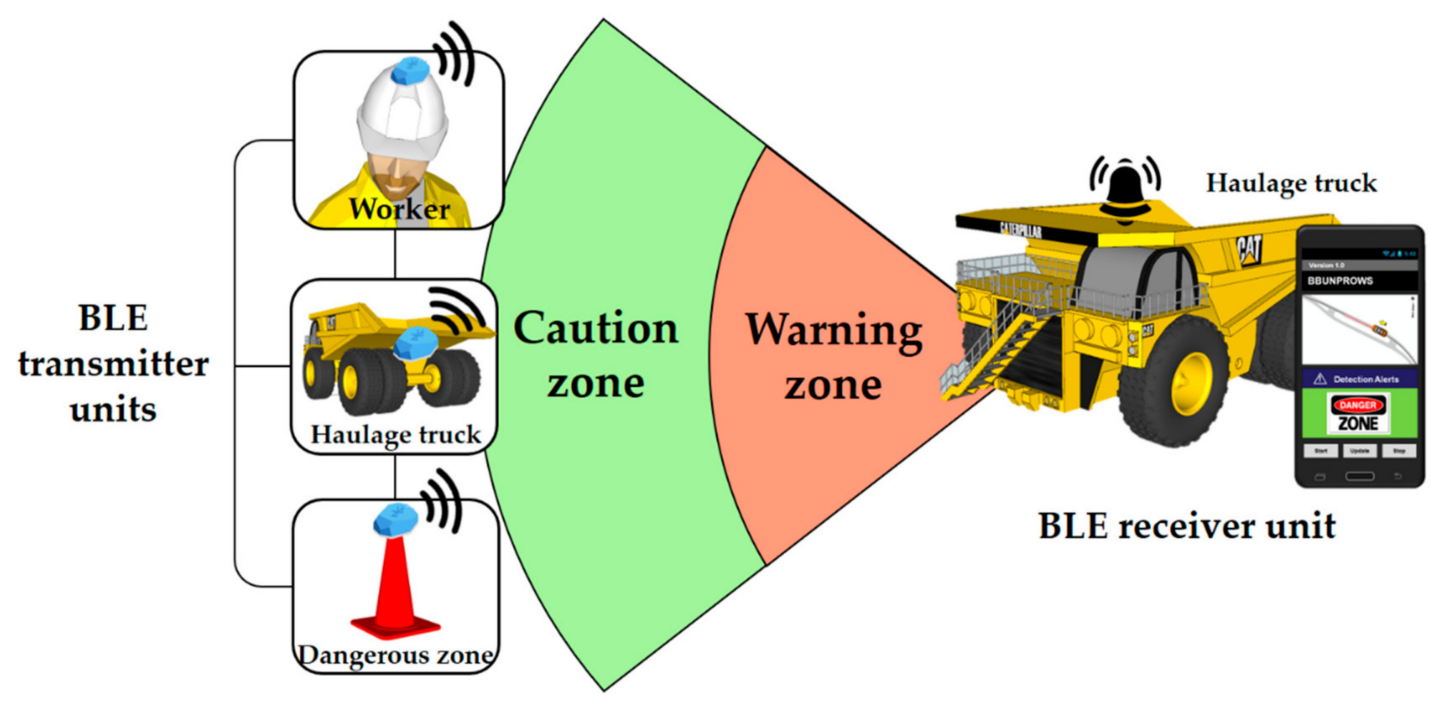

Figure 1. Conceptual diagram depicting Bluetooth low energy (BLE) transmitter and receiver units of the proposed Bluetooth-beacon-based underground proximity warning system (BBUNPROWS).

\subsection{Design of BLE Transmitter Units Using Bluetooth Beacons}

The transmission characteristics of Bluetooth beacons may vary depending on their orientation installation (Figure 2). For example, in the case of RECO beacons developed by Perples Inc. (Seoul, Korea), signals with transmission intensity set to $-4 \mathrm{dBm}$ can be propagated up to $70 \mathrm{~m}$ in front, $40 \mathrm{~m}$ to the back, and $30 \mathrm{~m}$ to the side of the beacon [20]. Signals propagating to the front and back of the beacon exhibit directionality, whereas those propagating to the side exhibit omnidirectionality. The proposed BBUNPROWS was designed to use omnidirectional signals generated from the sides of beacons, accomplished by attaching Bluetooth beacons in a horizontal orientation.

Figure 3 depicts examples of Bluetooth beacons installed on a worker's helmet, on the back of a vehicle, and at a potentially hazardous location. Bluetooth beacons attached to workers' helmets help drivers recognize workers approaching the caution and warning zones, even in dark workspaces, thereby preventing collisions. Bluetooth beacons installed at potentially hazardous locations provide alerts to drivers of the approach of vehicles towards a dangerous zone, thereby prompting safe driving. Inside underground tunnels, where vehicles move linearly along a fixed path, Bluetooth beacons can be installed on the rear of each vehicle, with a smartphone installed at the front to prevent collisions between vehicles. 

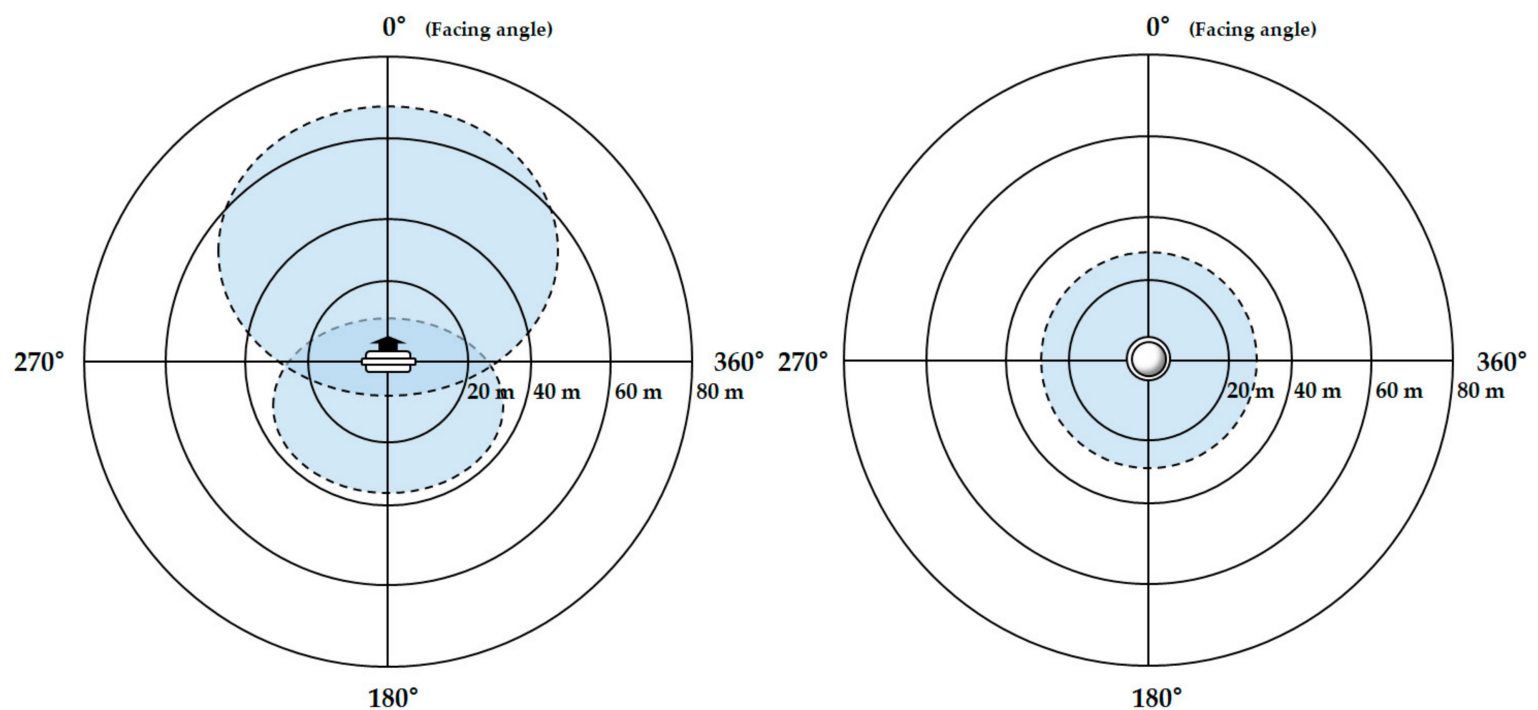

Figure 2. Propagation characteristics of a transmitted signal in accordance with the orientation of the Bluetooth-beacon installation.

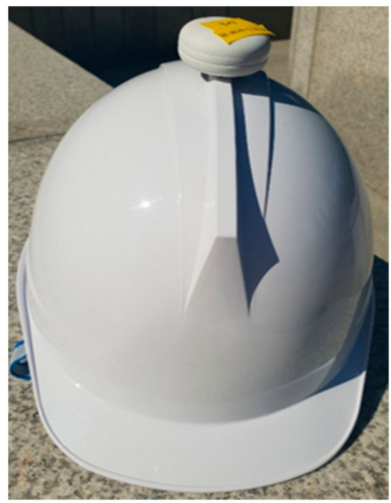

(a)

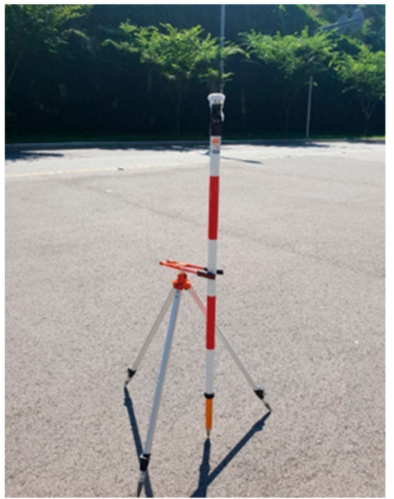

(b)

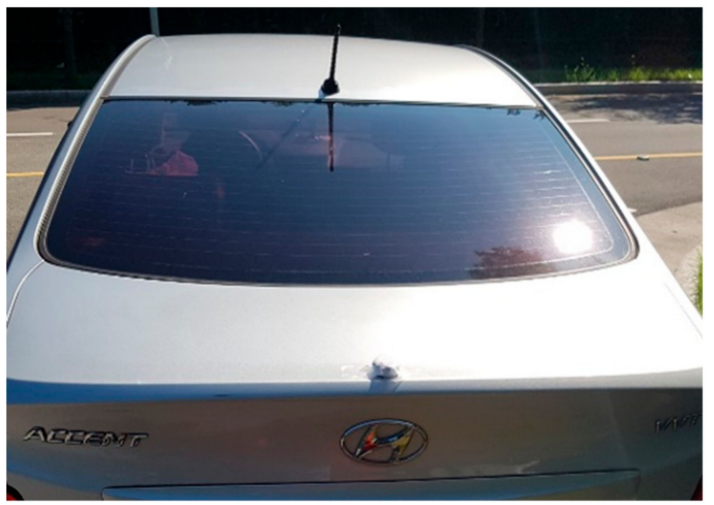

(c)

Figure 3. Examples of BLE transmitter units of BBUNPROWS with Bluetooth beacons attached to (a) a worker's helmet; (b) a danger-zone indicator; and (c) the rear of a vehicle.

\subsection{Design of BLE Receiver Units Using Smartphones}

The smartphone application for BBUNPROWS was developed using the MIT App Inventor [21] to work on the Android operating system (Google, Menlo Park, CA, USA). Figure 4 depicts conceptual diagrams of the user interface and database of the developed BBUNPROWS application. The database stores media access control (MAC) addresses of all Bluetooth beacons installed inside the underground tunnel, as well as alert images corresponding to each beacon.

BBUNPROWS separately manages information pertaining to Bluetooth navigation beacons for identifying current locations of equipment mounted with a smartphone, along with information concerning Bluetooth PWS beacons for detecting the approach of workers and other equipment. When a smartphone receives a signal from a navigation beacon, a navigation image corresponding to the MAC address of the said beacon is displayed on the screen. If the phone simultaneously receives signals from two or more navigation beacons, the RSSI values of the two signals are compared, and the navigation image corresponding to the beacon with greater reception strength appears [22]. 

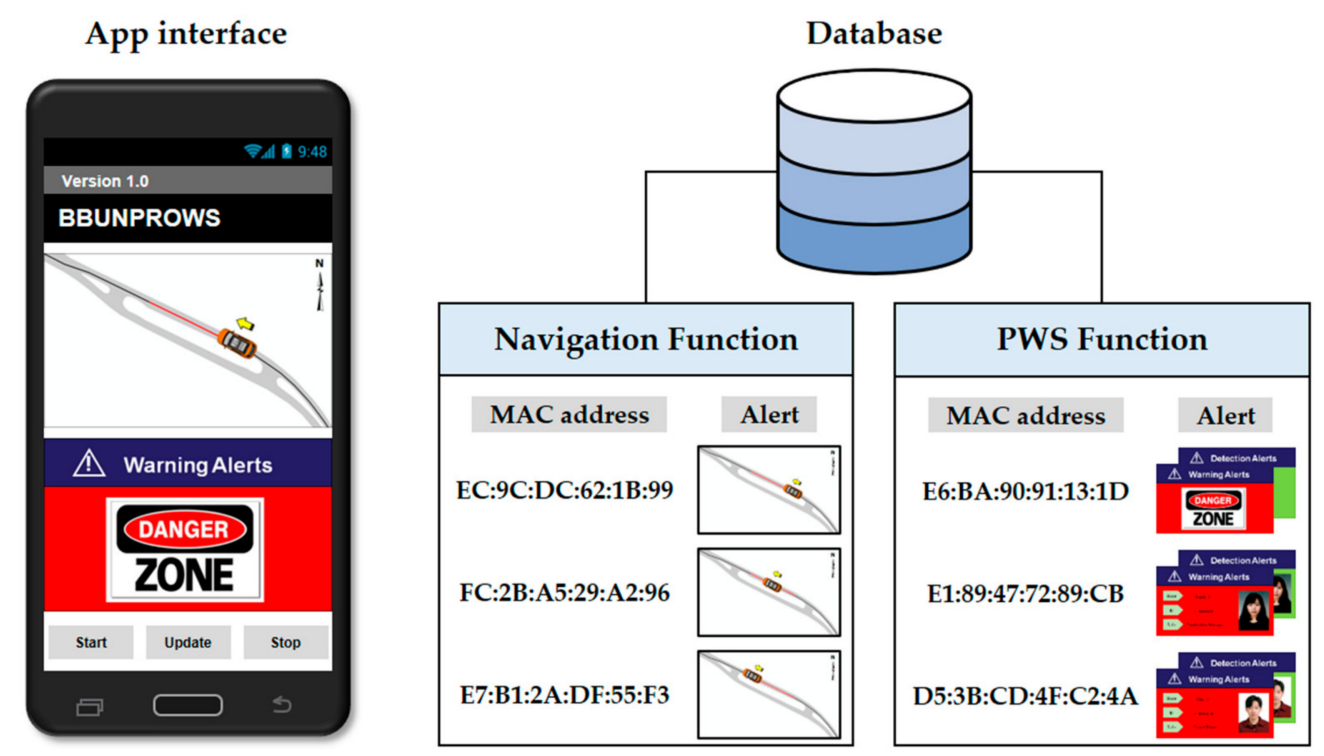

Figure 4. User interface and database of the BBUNPROWS smartphone application, including information pertaining to navigation and proximity warning system (PWS) functions.

When a smartphone receives a signal from a PWS beacon, the primary/caution and/or secondary/warning alert images are displayed based on the RSSI value. In other words, a primary/caution alert is issued if the PWS beacon's signal strength exceeds the RSSI threshold for the caution zone. Likewise, a secondary/warning alert is issued if the said signal strength exceeds the RSSI threshold for the warning zone. In the case of secondary/warning alerts, the smartphone application is designed to provide drivers with an audible warning (sound) in addition to the visual alert (image). Users can manually set RSSI thresholds for the caution and warning zones based on the characteristics of the workplace. The primary/caution and secondary/warning alert images are marked with green and red backgrounds, respectively, and display the name, organization name, and role of the worker or equipment driver, along with other information.

\section{Field Experiment Method}

The in-field applicability of BBUNPROWS was evaluated via experiments performed inside the Yeonhwa underground tunnel $\left(35^{\circ} 12^{\prime} 55^{\prime \prime} \mathrm{N}, 129^{\circ} 13^{\prime} 2^{\prime \prime}\right.$ E) located in Gijang-gun, Busan, Korea. The Yeonhwa underground tunnel measures $168 \mathrm{~m}, 20 \mathrm{~m}$, and $4.8 \mathrm{~m}$, in length, width, and height, respectively. Nine Bluetooth navigation beacons were installed on tunnel walls at 20-m intervals, starting from the point of entry into the underground tunnel $(0 \mathrm{~m})$ up to $160 \mathrm{~m}$. In addition, Bluetooth PWS beacons were attached to the safety helmets of pedestrian workers as well as to the rear of vehicles, as depicted in Figure 3.

Table 1 lists the specifications of RECO Bluetooth beacons (Perples Inc.; Seoul, Korea) employed during field experiments. The said RECO beacon can be operated for up to 24 months on a CR2450 lithium-ion battery (3 V, 620 mAh; Panasonic; Osaka, Japan) without the need for a separate power-supply system. The beacons have been certified by iBeacon (Apple; Santa Clara, CA, USA) and Eddystone (Google; Menlo Park, CA, USA), which adhere to global beacon standards, and have received major radio certifications in Korea as well as in the United States, Europe, and Japan. For the purpose of this study, the intensity of signals transmitted from the Bluetooth beacons was set to $4 \mathrm{dBm}$, with the cycle lasting $100 \mathrm{~ms}$.

A Samsung Galaxy S9 smartphone (Table 2) was mounted on each vehicle to receive signals transmitted by the Bluetooth beacons. To configure the application so that it would issue corresponding alerts when the caution and warning zones were located approximately $20 \mathrm{~m}$ and $10 \mathrm{~m}$ away from transmitting beacons, respectively, signals were received for five minutes from locations $10 \mathrm{~m}$ and $20 \mathrm{~m}$ 
away from Bluetooth beacons, and the corresponding RSSI value distributions were analyzed (Table 3). The observed mean RSSI values at locations $10 \mathrm{~m}$ and $20 \mathrm{~m}$ away from the beacons equaled $-83 \mathrm{dBm}$ and $-96 \mathrm{dBm}$, respectively. Because the purpose of BBUNPROWS was to prevent collisions inside underground tunnels, the RSSI thresholds for the caution and warning zones were set conservatively, with the set values representing a $\%$ cumulative percentage. Thus, the set threshold values equaled $-99 \mathrm{dBm}$ and $-91 \mathrm{dBm}$ for the caution and warning zones, respectively.

Table 1. Specifications of RECO beacons (Perples Inc.; Seoul, Korea) installed on safety helmets, safety equipment, and vehicles.

\begin{tabular}{|c|c|c|}
\hline \multicolumn{3}{|c|}{ Specifications } \\
\hline \multirow{3}{*}{ Appearance } & Dimensions (diameter $\times$ height) & $45 \mathrm{~mm} \times 20 \mathrm{~mm}$ \\
\hline & Weight (with battery) & $11.6 \mathrm{~g}$ \\
\hline & Casing & Acrylonitrile butadiene styrene (ABS) plastic \\
\hline \multirow{3}{*}{ Hardware } & Chipset & Nordic nRF51822 (Nordic Semiconductor; Oslo, Norway) \\
\hline & Processor & 32-bit ARM Cortex-M0 (ARM Holdings; Cambridge, UK) \\
\hline & Antenna & Omnidirectional built-in antenna \\
\hline \multirow{3}{*}{ Wireless Signal } & Wireless technology & Bluetooth ${ }^{\circledR}$ Smart 4.0 \\
\hline & Signal transmission period & Minimum $10 \mathrm{~ms}$, maximum $2 \mathrm{~s}$ \\
\hline & Transmission power & Minimum $-16 \mathrm{dBm}$, maximum $4 \mathrm{dBm}$ \\
\hline \multirow{4}{*}{ Certifications } & Korea & Korea Certification $(\mathrm{KC})$ \\
\hline & USA & Federal Communications Commission (FCC) \\
\hline & Europe & Conformié Européenne (CE) marking \\
\hline & Japan & Ministry of Internal Affairs and Communications (MIC) of Japan. \\
\hline
\end{tabular}

Table 2. Specifications of Samsung Galaxy S9 (SM-G960) smartphone used for analyzing received signal strength indicator (RSSI) distributions.

\begin{tabular}{cc}
\hline Model & Galaxy S9 (SM-G960) \\
\hline Operating System & Android 8.0 (Google; Menlo Park, CA, USA) \\
Android Processor & Exynos 9810 Octa (Samsung Electronics; Suwon, Korea) \\
Wireless & Bluetooth 5.0 \\
Technology & $4 \mathrm{~GB}$ \\
RAM & $3000 \mathrm{mAh}$ \\
Battery & \\
\hline
\end{tabular}

Table 3. Results of the statistical analysis of RSSI distributions.

\begin{tabular}{ccccccccc}
\hline \multirow{2}{*}{$\begin{array}{c}\text { Transmitted } \\
\text { Power }(\mathbf{d B m})\end{array}$} & $\begin{array}{c}\text { Range } \\
(\mathbf{m})\end{array}$ & Maximum & Minimum & Mode & Mean & $\begin{array}{c}\text { First } \\
\text { Quartile }\end{array}$ & $\begin{array}{c}\text { Second } \\
\text { Quartile }\end{array}$ & $\begin{array}{c}\text { Third } \\
\text { Quartile }\end{array}$ \\
\cline { 3 - 9 } & & & & & & & & \\
& 10 & -76 & -95 & -81 & -83 & -84 & -82 & -81 \\
4 & 20 & -85 & -100 & -98 & -96 & -99 & -97 & -94 \\
\hline
\end{tabular}

\section{Results}

Figure 5 depicts how the BBUNPROWS application performed on a smartphone-mounted vehicle when a worker wearing a PWS-beacon-mounted helmet was located in the study site along with a preceding vehicle. Until the worker entered the caution $(20 \mathrm{~m})$ or warning $(10 \mathrm{~m})$ zones near the vehicle, only the navigation image with vehicle position inside the tunnel was displayed on the smartphone screen, as depicted in Figure 5a. As the vehicle moved further and the worker entered the caution zone, a primary/caution alert was issued to the driver, as depicted in Figure 5b. Likewise, as the worker approached the warning zone, a secondary/warning alert was issued, as depicted in Figure 5c. It was also confirmed that when two vehicles approached each other, both primary/caution and secondary/warning alerts were issued to the driver in steps, based on the degree of proximity. 

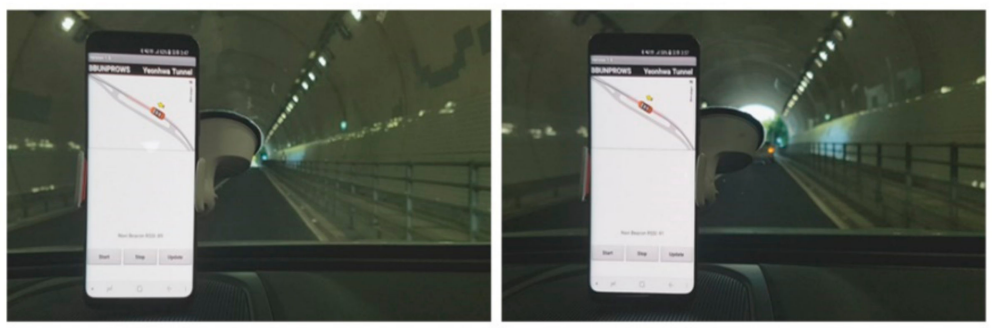

(a)
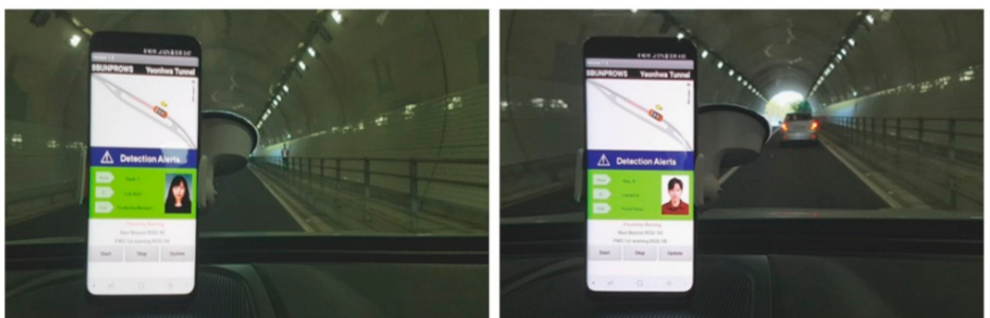

(b)
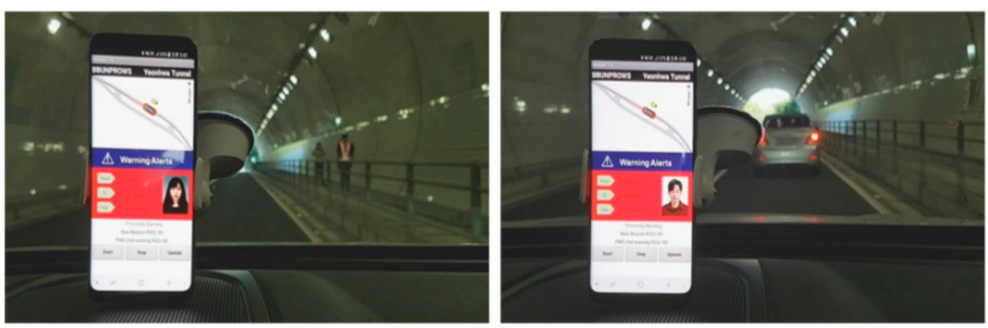

(c)

Figure 5. Results of field experiments-BBUNPROWS application displayed (a) vehicle location, (b) primary/caution alert, and (c) secondary/warning alert ahead of a worker (left images) and a passing vehicle (right images).

To analyze the accuracy of alerts issued to the driver by the BBUNPROWS application, the above experiment was repeated 50 times for the case in which a vehicle approached a pedestrian worker. Lengths of the caution and warning buffer zones were set in the range of $20-30 \mathrm{~m}$ and $10-20 \mathrm{~m}$, respectively, ahead of the vehicle along its direction of motion (Figure 6). Alerts issued by the BBUNPROWS application when the vehicle approached the worker at a speed of $10-20 \mathrm{~km} / \mathrm{h}$ in the tunnel were classified and analyzed as follows.

- True positives: Number of times that the alert was issued correctly when it ought to have been issued.

- True negatives: Number of times that the alert was not issued when it should have been issued.

- False positives: Number of times that the alert was issued when it should not have been issued.

- False negatives: Number of times that the alert was not issued when it should not have been issued.

- Accuracy: Ratio of the sum of true positives and true negatives to the sum of all events (true positives, true negatives, false positives, and false negatives). 


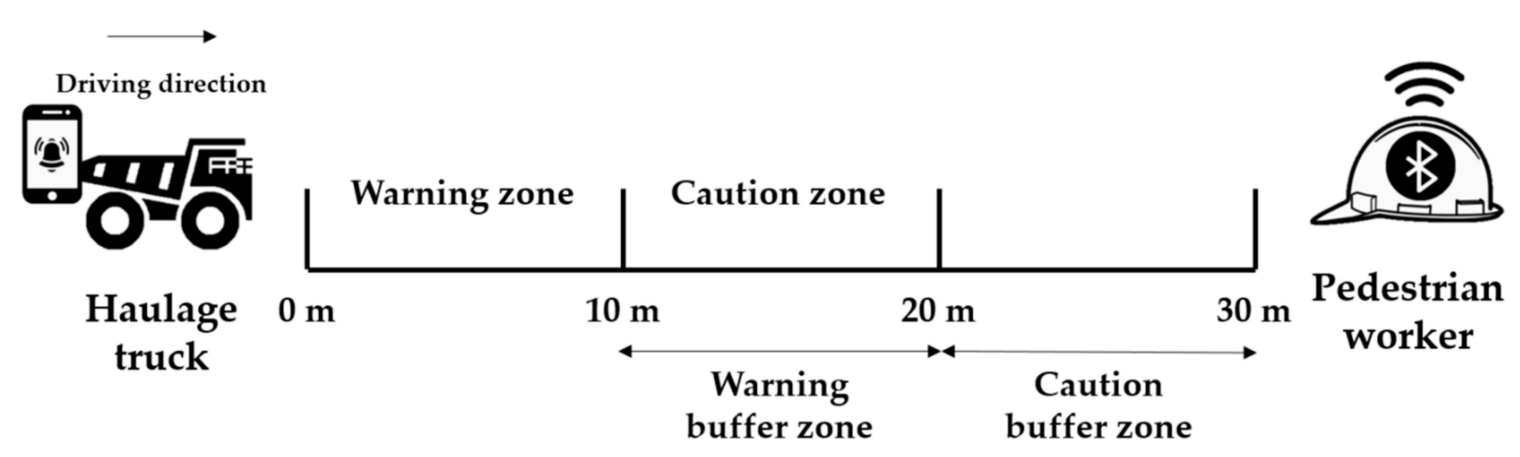

Figure 6. Conceptual view of process for assessing the accuracy of the proposed BBUNPROWS application when employed in Yeonhwa underground tunnel.

During the 50 repetitions of the above-described experiment, 50 true-positive primary and secondary alert scenarios were observed, whereas the number of false positives equaled 7 and 5 with regard to issuance of primary and secondary alerts, respectively. Zero false negatives were observed. The above results are summarized in Table 4 . In accordance with these results, the observed accuracy of the proposed BBUNPROWS application with regard to the issuance of primary/caution and secondary/warning equaled $93 \%$ and $95 \%$, respectively.

Table 4. Accuracy assessment of alerts issued by BBUNPROWS application.

\begin{tabular}{ccc}
\hline Type of Alert & $\begin{array}{c}\text { Primary/Caution Alert } \\
\text { (Caution Buffer Zone) }\end{array}$ & $\begin{array}{c}\text { Secondary/Warning Alert } \\
\text { (Warning Buffer Zone) }\end{array}$ \\
\hline No. of trials & 50 & 50 \\
No. of true positives & 50 & 50 \\
No. of true negatives & 43 & 45 \\
No. of false positives & 7 & 5 \\
No. of false negatives & 0 & 0 \\
Accuracy (\%) & 93 & 95 \\
\hline
\end{tabular}

\section{Discussion}

\subsection{Comparison of RSSI Distributions Measured on the Surface and Inside an Underground Tunnel}

To facilitate the comparison of RSSI distributions of BLE signals received on the surface outside the underground tunnel, RSSIs were received for five minutes at distances of $10 \mathrm{~m}$ to $20 \mathrm{~m}$ away from the Bluetooth beacons in an open area of the Pukyong National University in Busan, Korea. Other experimental conditions were maintained as constants. Table 5 summarizes the RSSI distribution characteristics observed on surface. Observed mean RSSI values at distances of $10 \mathrm{~m}$ and $20 \mathrm{~m}$ measured $-85.1 \mathrm{dBm}$ and $-95.4 \mathrm{dBm}$, respectively. When compared with RSSI distributions measured inside the underground tunnel (Table 3), results corresponding to surface measurements did not demonstrate a large difference. This implies that the findings reported in previous studies on Bluetooth-beacon-based PWSs with regard to their use in civil and construction industries [17-19] are equally applicable in mining-industry applications.

Table 5. Results of statistical analysis of the RSSI distribution of BLE signals received on the surface.

\begin{tabular}{ccccccccc}
\hline \multirow{2}{*}{$\begin{array}{c}\text { Transmission Power } \\
(\mathbf{d B m})\end{array}$} & $\begin{array}{c}\text { Range } \\
\mathbf{( m )}\end{array}$ & $\mathbf{M a x}$ & Min & Mode & Mean & Q1 & Q2 & Q3 \\
\cline { 3 - 9 } & 10 & -76 & -100 & -82 & -85.1 & -88 & -85 & -82 \\
\multirow{2}{*}{4} & 20 & -86 & -100 & -98 & -95.4 & -98 & -96 & -94 \\
\hline
\end{tabular}




\subsection{Implications for Underground Mines}

The nature of work performed inside underground mines concerns the movement of employees as well as that of vehicles over complicated underground terrain. Therefore, the technical environment associated with underground mining excavations imposes many limitations on the utility of radio systems employed in mines. For example, there exist excavations with small cross-sections, long lengths, and at times, short dimensions connected with crossings inclined at 90 degrees or less with respect to one another. In general, the number of excavation connections depends on the size of the mining area and the system of exploitation of natural-resource deposits. In addition, a large number of electrical installations and devices with high power requirements are required when performing underground excavations. These installations generate electromagnetic fields. In addition to this, there exists high humidity (often above $80 \%$ relative humidity), salinity, and dust particles in the air, along with metallic equipment and associated waste in the vicinity of mining excavations.

The above factors mandate that Bluetooth-beacon-based equipment must possess required levels of effective sealing against the intrusion of surrounding environmental elements. Attenuation of radio waves by rock mass is also a significant factor which must be accounted for in the development of beacon-based systems, owing to presence of numerous intersections within excavation sites. Suppression of radio waves within different rock structures must, therefore, be analyzed for a given type of wireless communication network.

In addition, the high power levels of radio-transmission devices should not cause the accidental firing of explosives, given the small distance of blasting circuits from radio-transmission devices at excavation sites. With regard to gas mines, all equipment used inside underground excavations must be protected against spark ignition and be used in an explosion-proof manner. Although the proposed study assumes smartphones to be an integral part of vehicles, the use of personal smartphones in underground mines has often proven to be problematic.

\section{Conclusions}

The proposed study reports the development of a Bluetooth-beacon-based underground proximity warning system (BBUNPROWS) capable of receiving signals from Bluetooth beacons installed on the bodies of pedestrian workers, equipment, and at dangerous locations inside underground tunnels, which provide potential collision-risk alerts based on RSSI values of signals received. Field experiments were performed using the proposed BBUNPROWS inside an underground tunnel in Busan, Korea. The results of said experiments demonstrate that when a pedestrian worker or vehicle installed with a Bluetooth beacon enters a caution or warning zone, the extent of which typically starts from $20 \mathrm{~m}$ and $10 \mathrm{~m}$ upstream of the vehicle, respectively, the system successfully issues primary (caution) and secondary (warning) alerts to drivers. Furthermore, the said experiment was repeated 50 times, thereby demonstrating that the accuracy of issuance of the primary and secondary alerts corresponding to entry into the caution and warning zones equaled $93 \%$ and $95 \%$, respectively.

The proposed Bluetooth-beacon-based PWS possesses the following advantages over the existing PWSs employed in underground tunnels:

1. Bluetooth beacons that transmit BLE signals do not require an external power source, because they receive power from a coin battery. Therefore, no additional infrastructure is required for supplying power to underground mines.

2. The system is cost competitive because Bluetooth beacons are inexpensive, and there is no need to set up a separate signal reception terminal, since smartphones are used as receptors.

3. Existing systems necessitate the installation of large and heavy antennas as part of production equipment and mining structures for installing wireless signal transmitters. However, Bluetooth beacons, being small and lightweight, can be easily installed anywhere inside underground mines. In addition, Bluetooth beacons are made of sturdy materials and are less vulnerable to humidity; this makes them especially suitable for use in underground mining sites. 
4. The proposed PWS system can be extended by adding new functions using the Bluetooth beacon software development kit (SDK) and Android application programming interface (API).

5. The BBUNPROWS application can be shared as open source. Therefore, it is expected that the proposed Bluetooth-beacon-based PWS can effectively be introduced at low cost for use in underground tunnels and safety management.

Although the proposed BBUNPROWS application has been successfully tested for use in underground tunnels, the results obtained do not guarantee that it can be reliably used in underground mines. This is because operating conditions in underground mines are significantly different from those in underground tunnels. Therefore, further experimental research must be performed concerning the use of BBUNPROWS in underground mines.

Author Contributions: Y.C. conceived and designed the experiments; J.B. performed the experiments; J.B. and Y.C. analyzed the data; Y.C. contributed reagents/materials/analysis tools; J.B. and Y.C. wrote the paper.

Funding: This work was supported by (1) Institute for Information \& communications Technology Promotion (IITP) grant funded by the Korea Government's Ministry of Science and ICT (Project No. 2018-0-01282) and (2) Korea Energy and Mineral Resources Engineering Program funded by the Korea Government's Ministry of Trade, Industry and Energy.

Conflicts of Interest: The authors declare no conflict of interest.

\section{References}

1. Mine Safety and Health Administration (MSHA). Historical Data on Mine Disasters in the United States. Available online: https://arlweb.msha.gov/mshainfo/factsheets/mshafct8.htm (accessed on 22 August 2018).

2. Centers for Disease Control and Prevention (CDC). Mining Topic: Proximity Detection. Available online: https:/ / www.cdc.gov/niosh/mining/topics/ProximityDetection.html (accessed on 22 August 2018).

3. Centers for Disease Control and Prevention (CDC). Occupational Fatalities by Accident Class at Underground Mining Locations, 2011-2015. Available online: https:/ /www.cdc.gov/niosh/mining/UserFiles/statistics/ 15g06uaa.svg (accessed on 22 August 2018).

4. Schiffbauer, W.H. An Active Proximity Warning System for Surface and Underground Mining Applications. Miner. Eng. 2002, 54, 40-48.

5. Ruff, T.M. Recommendations for Evaluating and Implementing Proximity Warning Systems on Surface Mining Equipment. Available online: https://stacks.cdc.gov/view/cdc/8494 (accessed on 22 August 2018).

6. Ruff, T.M. Overview of Proximity Warning Technology and Approaches. Available online: https://www.cdc. gov/niosh/mining/userfiles/workshops/proximityworkshop2010/ruff-niosh-pdworkshop2010-508.pdf (accessed on 22 August 2018).

7. Ruff, T.M. Test Results of Collision Warning Systems for Surface Mining Dump Trucks. Available online: https://www.cdc.gov/niosh/mining/userfiles/works/pdfs/ri9652.pdf (accessed on 22 August 2018).

8. Ruff, T.M. Test Results of Collision Warning Systems on Off-Highway Dump Trucks: Phase 2. Available online: https:/ /www.cdc.gov/niosh/mining/UserFiles/works/pdfs/2001-100.pdf (accessed on 22 August 2018).

9. Ruff, T.M.; Hession-Kunz, D. Application of Radio-frequency Identification Systems to Collision Avoidance in Metal/nonmetal mines. IEEE Trans. Ind. Appl. 2001, 37, 112-116. [CrossRef]

10. Becker Mining. Proximity Detection and Collision Avoidance System. Available online: http://www.undergroundcoal. com.au/acarp_dev/May\%202011/Proximity\%20Detection\%20and\%20Collision\%20Avoidance\%20-\%20Stephan\% 20Becker.pdf (accessed on 22 August 2018).

11. Mine Site Technologies. IMPACT Technology. Available online: http://mstglobal.com/wp-content/ uploads/2016/09/MST_ProximityDetection_Overview_en.pdf (accessed on 22 August 2018).

12. PBE Group. Proximity Alert System (PAS). Available online: http://pbegrp.com/mining-solutions/ proximity-alert-system (accessed on 22 August 2018).

13. STRATA Worldwide. HazardAvert Surface and Underground. Available online: https://www. strataworldwide.com/proximity-detection/surface-and-underground (accessed on 22 August 2018). 
14. Nautilus International. Buddy Proximity Detection System. Available online: http://www. nautilus-intl.com/proximity-detection/nautilus-coal-buddy-operators-proximity-detection-systemfor-underground-coal-mines-operating-in-an-explosive-methane-gas-environment-class-i-div-ii/ (accessed on 22 August 2018).

15. Jung, J.; Choi, Y. Measuring Transport Time of Mine Equipment in and Underground Mine Using a Bluetooth Beacon System. Minerals 2017, 7, 1. [CrossRef]

16. Baek, J.; Choi, Y.; Lee, C.; Jung, J. Performance Comparison of Bluetooth Beacon and Reverse RFID Systems as Potential Tools for Measuring Truck Travel Time in Open-pit Mines: A Simulation Experiment. Geosyst. Eng. 2018, 21, 43-52. [CrossRef]

17. Park, J.; Marks, E.; Cho, Y.K.; Suryanto, W. Performance Test of Wireless Technologies for Personnel and Equipment Proximity Sensing in Work Zones. J. Constr. Eng. Manag. 2016, 142. [CrossRef]

18. Park, J.; Kim, K.; Cho, Y.K. Framework of Automated Construction-Safety Monitoring Using Cloud-Enabled BIM and BLE Mobile Tracking Sensors. J. Constr. Eng. Manag. 2017, 143. [CrossRef]

19. Park, J.; Yang, X.; Cho, Y.K.; Seo, J. Improving dynamic proximity sensing and processing for smart work-zone safety. Autom. Constr. 2017, 84, 111-120. [CrossRef]

20. RECO Beacon. Available online: http:/ / reco2.me/ (accessed on 22 August 2018).

21. MIT App Inventor. Available online: http://appinventor.mit.edu/explore/ (accessed on 22 August 2018).

22. Baek, J.; Choi, Y.; Lee, C.; Suh, J.; Lee, S. BBUNS: Bluetooth Beacon-Based Underground Navigation System to Support Mine Haulage Operations. Minerals 2017, 7, 1-16. [CrossRef]

(C) 2018 by the authors. Licensee MDPI, Basel, Switzerland. This article is an open access article distributed under the terms and conditions of the Creative Commons Attribution (CC BY) license (http:/ / creativecommons.org/licenses/by/4.0/). 